\title{
EXPERIMENTAL STUDY ON THE EFFICIENT DEHYDRATION OF DREDGED SLUDGE WITH A COMPACT FILTER PRESS
}

\author{
Tomoaki TAKISAWA' ${ }^{\text {, Akira MURAKAMI }}{ }^{2}$ and Shin'ichi NISHIMURA ${ }^{3}$ \\ ${ }^{1}$ Student, Graduate School of Environmental Science, Okayama University \\ (1-1,Tsushima-Naka, 3-chome, Okayama 700-8530, Japan) \\ E-mail: dev18104@cc.okayama-u.ac.jp \\ 2 Professor, Graduate School of Environmental Science, Okayama University \\ (1-1,Tsushima-Naka, 3-chome, Okayama 700-8530, Japan) \\ E-mail: akira_m@cc.okayama-u.ac.jp \\ 3 Associate Professor, Graduate School of Environmental Science, Okayama University \\ (1-1,Tsushima-Naka, 3-chome, Okayama 700-8530, Japan) \\ E-mail: theg1786@cc.okayama-u.ac.jp
}

\begin{abstract}
The disposal of large amounts of sludge, deposited in many farm/irrigation ponds in Japan, has recently become an important task to be resolved. To dredge sludge helps to maintain the capacity of the ponds and the quality of the water in the pond. In other words, it is vital that the deposited sludge should be effectively dredged. Since the water content of dredged sludge is very high, it must be reduced to enable the transport and the reuse of the sludge. The authors of the present paper have developed a procedure to dehydrate in-situ dredged sludge from farm ponds using a compact filter press machine. The purpose of this study is to investigate appropriate conditions for the efficient dehydration of dredged sludge with a compact filter press machine. Since the dehydration mechanism inside the filter press machine is based on the hydraulic consolidation, hydraulic consolidation tests are conducted to simulate the filter press consolidation in order to clarify the relationship between the conditions of the filter press dehydration and the water content of the consolidated sludge. Results of the tests show that the most important factor in controlling the efficiency of the actual filter press dehydration process is the thickness of the filtration chamber of the filter press machine. Sludge is expected to be more effectively dehydrated when a filtration chamber with a smaller thickness is adopted.
\end{abstract}

Key Words : Filter press, Hydraulic consolidation, Dredged sludge, Coagulant

\section{INTRODUCTION}

Large amount of sludge is deposited within a depth of $1 \mathrm{~m}$ in over 210,000 farm ponds in Japan. Much of the deposited sludge is dredged from the bottom of farm ponds in order to improve efficiency of the ponds for water storage. The dredged soils are treated by means of several techniques, e.g., solidification by stabilizing materials, mechanical dehydration, desiccation, and heat stabilization, so that they may be reused as construction material after the water content of the soils is reduced.
Previous works related to the treatment of clayey soils dredged from lakes and irrigation ponds can be listed as follows. Fukushima et al. (2000) examined the applicability of cement-stabilized mud soil as embankment material for use in repairing irrigation ponds. Hidaka et al. (2006) demonstrated that filter presses are typically capable of decreasing the water content up to $30 \%-60 \%$. Nishimura et al. (2007) presented the mechanical characteristics of the dredged sludge from Kojima Lake in Okayama Prefecture which is made into cakes by a filter press machine for reuse as construction material. Sludge, 
Table 1 Results of the XRF analyses.

\begin{tabular}{|c|cc|}
\hline Analysis & Sample A & Sample B \\
\hline $\mathrm{SiO}_{2}$ & 53.60 & 61.09 \\
$\mathrm{Al}_{2} \mathrm{O}_{3}$ & 20.05 & 18.44 \\
$\mathrm{Fe}_{2} \mathrm{O}_{3}$ & 4.92 & 6.75 \\
$\mathrm{CaO}$ & 0.98 & 1.80 \\
$\mathrm{MgO}$ & 0.60 & 0.57 \\
$\mathrm{Na} 2$ & 1.19 & 0.09 \\
$\mathrm{~K}_{2} \mathrm{O}$ & 2.11 & 2.56 \\
$\mathrm{Cr}_{2} \mathrm{O}_{3}$ & $<0.01$ & 0.00 \\
$\mathrm{TiO}_{2}$ & 0.60 & 1.05 \\
$\mathrm{MnO}_{2 n}$ & 0.06 & 0.11 \\
$\mathrm{P}_{2} \mathrm{O}_{5}$ & 0.24 & 5.70 \\
$\mathrm{SrO}$ & 0.01 & 0.02 \\
$\mathrm{BaO}$ & 0.05 & 0.02 \\
\hline
\end{tabular}

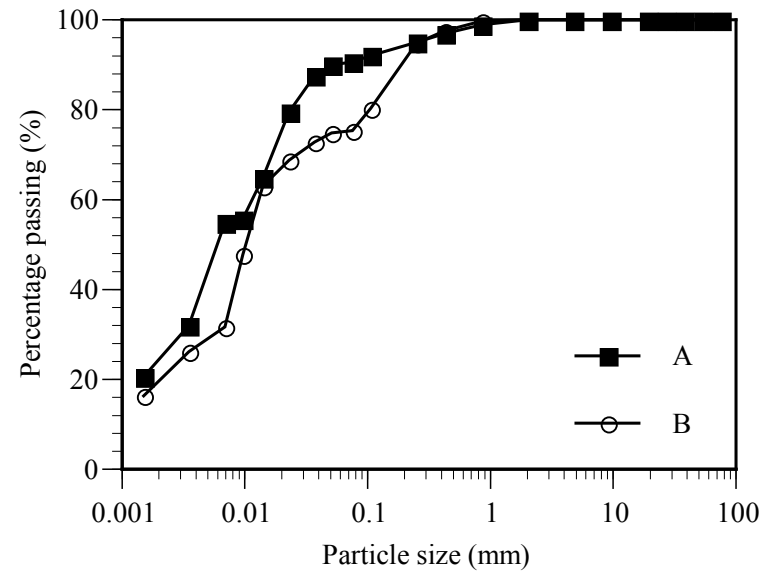

Fig.1 Particle size distribution curves of the sludge.

Table 2 Physical and chemical properties of the sludge.

\begin{tabular}{|r|r|r|r|r|r|r|r|}
\hline & \multicolumn{1}{|c|}{$\mathrm{W}_{\mathrm{L}}(\%)$} & \multicolumn{1}{c|}{$\mathrm{W}_{\mathrm{P}}(\%)$} & \multicolumn{1}{c|}{$\mathrm{Ip}$} & $\mathrm{Li}(\%)$ & \multicolumn{1}{c|}{$\mathrm{pH}$} & $\mathrm{EC}(\mathrm{mS} / \mathrm{cm})$ & $\rho_{\mathrm{s}} \mathrm{g} / \mathrm{cm} 3$ \\
\hline $\mathrm{A}-\mathrm{N}$ & 175.0 & 44.2 & 130.8 & 12.1 & 6.4 & 0.35 & 2.49 \\
$\mathrm{~A}-\mathrm{C}$ & 137.0 & 55.6 & 81.4 & 11.3 & 6.2 & 0.60 & 2.52 \\
$\mathrm{~B}-\mathrm{N}$ & 165.5 & 47.5 & 118.0 & 13.7 & 6.4 & 0.26 & 2.43 \\
$\mathrm{~B}-\mathrm{C}$ & 129.5 & 59.8 & 69.7 & 10.9 & 6.0 & 0.79 & 2.51 \\
\hline
\end{tabular}

which can be stabilized for reuse by cement or by a chemical mixture, is mainly made into construction material. On the other hand, filter press machines are installed at only a limited number of sites.

Special focus is herein placed on a small type of filter press machine which can be carried to the site of farm ponds by a four-ton truck to treat dredged sludge by mechanical compulsory dehydration and without decreasing the water level of the ponds. In this paper, the results obtained and the observations made during an extensive laboratory investigation of hydraulic consolidation tests from the viewpoints of consolidation pressure, the consolidation period, the initial water content, and the amount of dehydrated sludge, which all lead to the filter press machine providing maximum filtration efficiency.

\section{EXPERIMENTAL MATERIALS}

Sludge used for several experiments appeared in subsequent sections are dredged from farm ponds in Kagawa prefecture to examine characteristics of different specimen affected by specific factors of each pond. Soil specimens from the two ponds as original sludge are designated as Samples A and B. The dredged sludge is mixed with a stabilizer and dehydrated with the filter press machine to be made as sludge cake. Two types of sludge, namely, the original and the dehydrated, are referred to as ' $\mathrm{N}$ ' and 'C', respectively.
Table 1 lists the results of the XRF analyses in which $\mathrm{SiO} 2$ is found to be the most dominant component of the materials. The fraction rates of the mineral components are similar for Samples A and B.

\section{PHYSICOCHEMICAL BEHAVIOR OF SLUDGE}

Table 2 shows the physical and the chemical properties of Samples A and B. As seen in the table, the ignition loss is $12 \%$ for both samples. The liquid limits of the dehydrated materials, Samples A-C and B-C are smaller than those of original sludge Samples A-N and B-N. For the plastic limits, on the other hand, Samples A-C and B-C are larger than those of original sludge Samples A-N and B-N, because the sludge improved by coagulant can contain more moisture inside than the original sludge. Fig.1 shows the particle size distribution curves of the materials. According to this figure, the fine contents of the materials are quite large, namely, $90 \%$ for $\mathrm{A}$ and $75 \%$ for B, respectively.

\section{FILTRATION TESTS}

Filtration tests using four different types of filter materials are carried out. Table $\mathbf{3}$ shows the specifications of the filters. Four types of filters are 
Table 3 Filter specifications.

\begin{tabular}{|c|c|c|c|c|c|}
\hline & Material & Roughness & $\begin{array}{c}\text { Thickness } \\
(\mathrm{mm})\end{array}$ & $\begin{array}{c}\text { Air permeability } \\
(\mathrm{cc} / \mathrm{cm} 2 \mathrm{~s})\end{array}$ & $\begin{array}{c}\text { Filtration time } \\
(\mathrm{min})\end{array}$ \\
\hline Filter A & polyamide & $\mathrm{F}$ & 1.00 & 37 & 51 \\
Filter B & polyamide & $\mathrm{M}$ & 0.68 & 25 & 5 \\
Filter C & polypropylene & $\mathrm{S}$ & 1.00 & 11 & 85 \\
Filter D & polyamide & $\mathrm{F}$ & 1.03 & 5 & 51 \\
\hline
\end{tabular}

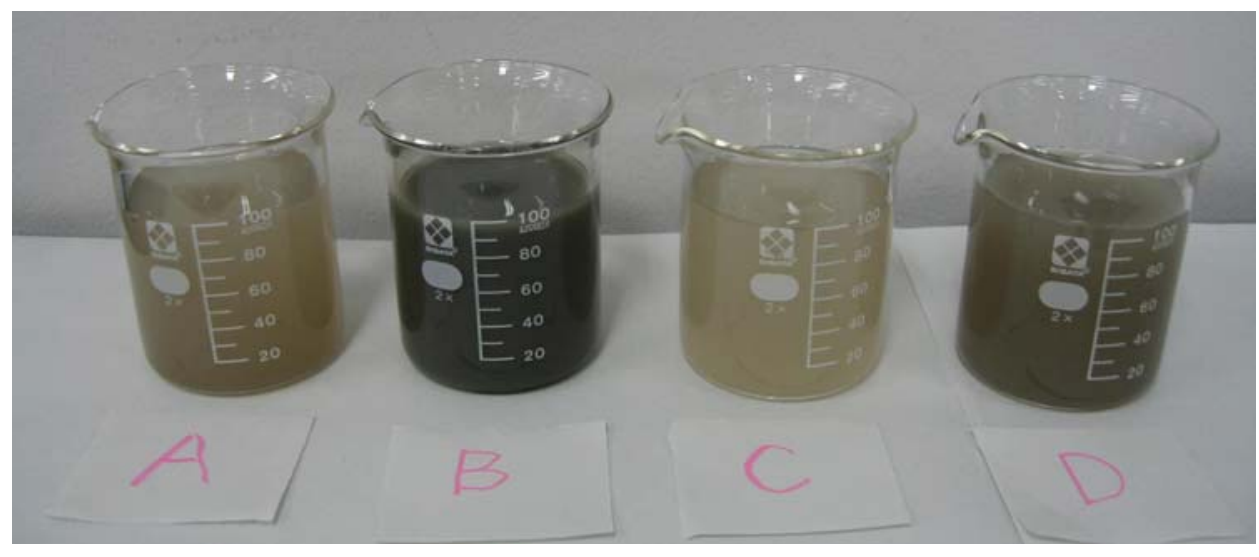

Fig.2 Results of the turbidimetric tests.

Table 4 Test conditions.

\begin{tabular}{|c|c|c|c|c|c|c|}
\hline & Filter & $\begin{array}{c}\text { Flocculant } \\
\left(1 / \mathrm{m}^{3}\right)\end{array}$ & $\begin{array}{l}\text { Time } \\
\text { (hour) }\end{array}$ & $\begin{array}{c}\text { Pressure } \\
(\mathrm{kPa})\end{array}$ & $\begin{array}{c}\text { Amount } \\
(\mathrm{kg})\end{array}$ & $\begin{array}{l}\mathrm{W}_{0} \\
(\%)\end{array}$ \\
\hline \multirow{4}{*}{ Figure 5} & Filter A & \multirow{4}{*}{ untreated } & \multirow{4}{*}{2} & \multirow{4}{*}{300} & \multirow{4}{*}{1} & \multirow{4}{*}{380} \\
\hline & Filter B & & & & & \\
\hline & Filter C & & & & & \\
\hline & Filter D & & & & & \\
\hline \multirow{3}{*}{ Figure 6} & \multirow{3}{*}{ Filter D } & 0.15 & \multirow{3}{*}{2} & \multirow{3}{*}{300} & \multirow{3}{*}{1} & \multirow{3}{*}{380} \\
\hline & & 0.20 & & & & \\
\hline & & 0.40 & & & & \\
\hline \multirow{3}{*}{ Figure 7} & \multirow{3}{*}{ Filter D } & \multirow{3}{*}{ untreated } & 1 & \multirow{3}{*}{300} & \multirow{3}{*}{1} & \multirow{3}{*}{380} \\
\hline & & & 2 & & & \\
\hline & & & 3 & & & \\
\hline \multirow{3}{*}{ Figure 8} & \multirow{3}{*}{ Filter D } & untreated & \multirow{3}{*}{2} & 100 & \multirow{3}{*}{1} & \multirow{3}{*}{380} \\
\hline & & (inticaten & & 300 & & \\
\hline & & 0.4 & & 500 & & \\
\hline \multirow{5}{*}{ Figure 9} & \multirow{5}{*}{ Filter D } & \multirow{5}{*}{ untreated } & \multirow{5}{*}{2} & \multirow{5}{*}{300} & 0.25 & \multirow{5}{*}{380} \\
\hline & & & & & 0.50 & \\
\hline & & & & & 0.75 & \\
\hline & & & & & 1.00 & \\
\hline & & & & & 2.00 & \\
\hline \multirow{5}{*}{ Figure 10} & \multirow{5}{*}{ Filter D } & \multirow{5}{*}{ untreated } & \multirow{5}{*}{2} & \multirow{5}{*}{300} & & 215 \\
\hline & & & & & & 294 \\
\hline & & & & & 1 & 373 \\
\hline & & & & & & 452 \\
\hline & & & & & & 530 \\
\hline
\end{tabular}




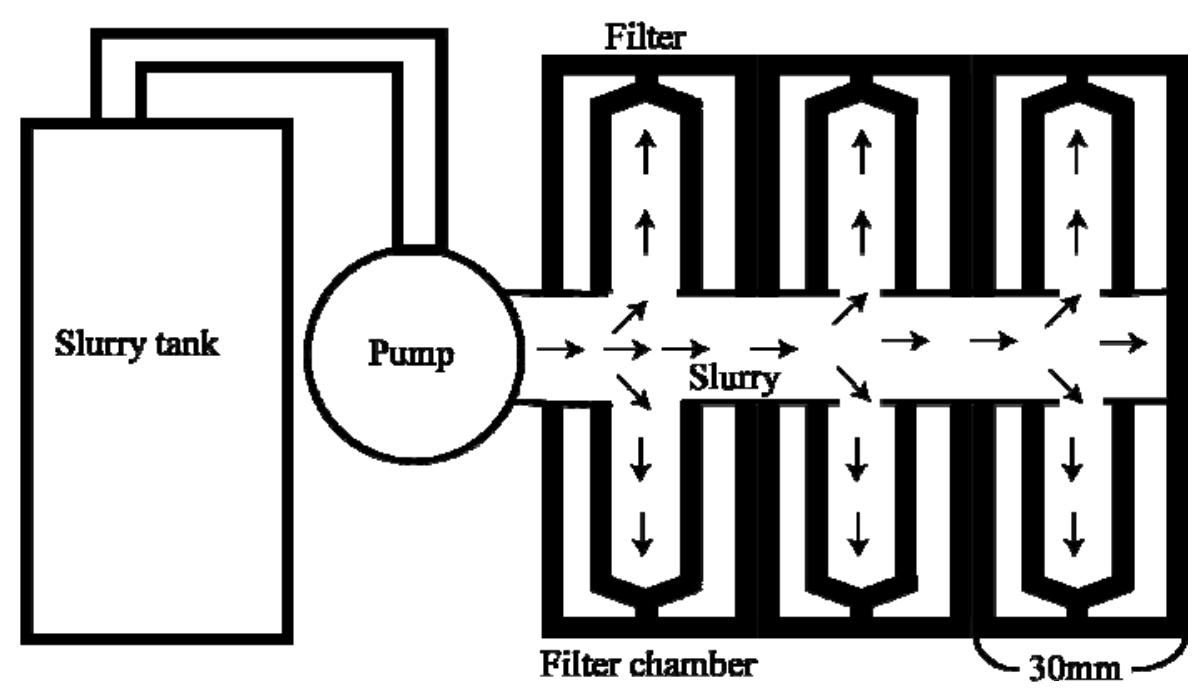

Fig.3 Filter press machine.

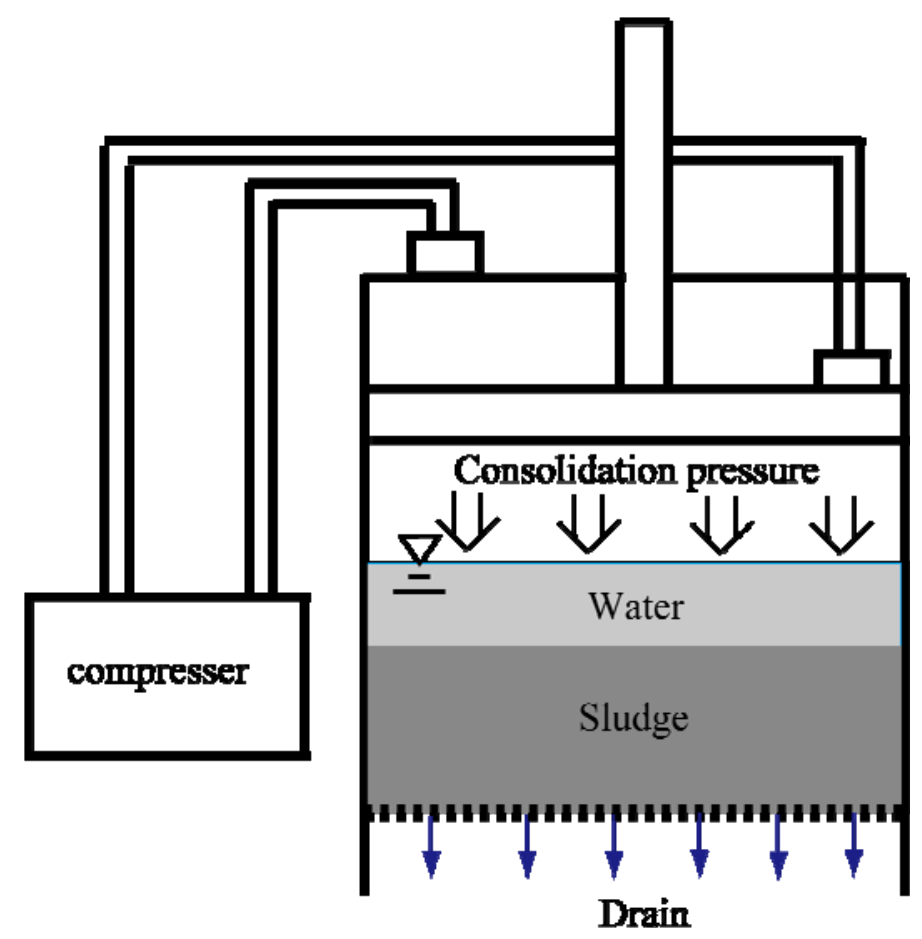

Fig.4 Hydraulic consolidation device.

used for various quantities of air permeability, namely, Filter A) $37 \mathrm{cc} / \mathrm{cm} 2 \mathrm{~s}$, Filter B) $25 \mathrm{cc} / \mathrm{cm} 2 \mathrm{~s}$, Filter C) $11 \mathrm{cc} / \mathrm{cm} 2 \mathrm{~s}$, and Filter D) $5 \mathrm{cc} / \mathrm{cm} 2 \mathrm{~s}$. Filters A, B, and D are made from polyamide, while Filter C is made from polypropylene. The test slurry is prepared by adding water to the original slurry to have the water content of $150 \%$ which falls between plastic limit and liquid limit, and the slurry is leached by four filters. Filtration time, which is defined for sludge of $100 \mathrm{ml}$ to be filtrated, is evaluated to be 51 , 5 , and 85 minutes for filter $\mathrm{A} / \mathrm{D}, \mathrm{B}$, and $\mathrm{C}$, respectively. It is revealed that the filter $B$ consumes a least time for filtration among four filters.

Fig.2 compares four types of water filtrated through the different filter materials. It can be seen that the turbidity of filtrated water with Filter B is higher than with other filters, although the filtration time of filter B is shorter than that of other filters. While, the filter $\mathrm{C}$ takes very long time to filtrate the water, though it can decrease the turbidity drastically. The fine type filters take longer time to filtrate the water than the rough type filters, though they can decrease turbidity. In the field test, the sample with short dehydration time is used for filtration because the water content of dehydrated sludge does not change with the filter types. Filter D is adopted for a series of tests in subsequent sections from the viewpoint of dehydration time, because the turbidity of filter D is quite low, whereas its filtration time is less than that of filter B. 


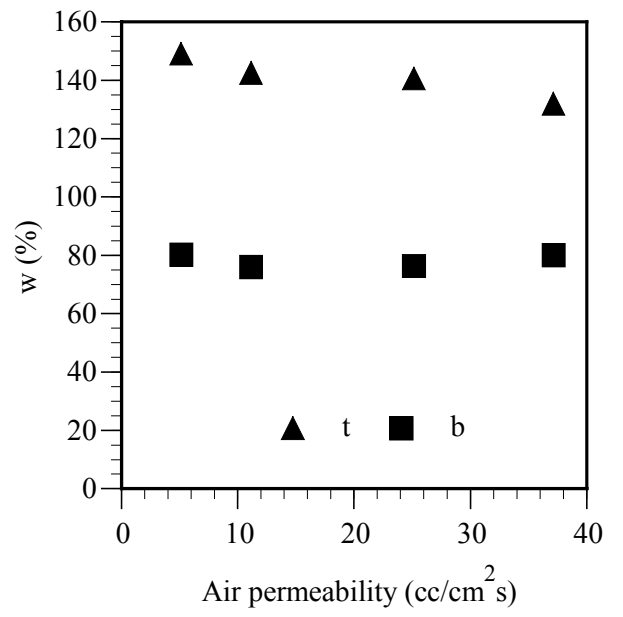

Fig.5 Relationship between the water content and the air permeability.

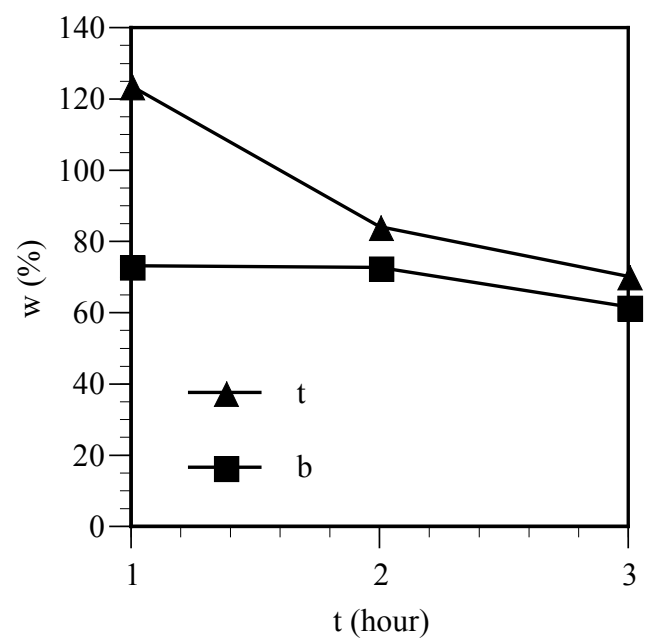

Fig.7 Relationship between the water content and the consolidation time.

\section{HYDRAULIC CONSOLIDATION TESTS}

Fig.3 emulates the structure inside the filter press machine, where sludge is dehydrated by pumping the slurry into the filter chamber at the pressure of around $300 \mathrm{kPa}$. Since the consolidation mechanism of the filter press is similar to that of hydraulic consolidation, laboratory hydraulic consolidation tests (e.g., Imai 1979) are conducted using Sample A to simulate the filter press consolidation. The hydraulic consolidation test device is presented in Fig.4. The air pressure is applied to the column and the sludge is filtrated by the filter. Table $\mathbf{4}$ describes the test conditions, where the first column shows the figure numbers of conducted tests, the second is the filter type used in the test, the third is the consolidation time, the fourth is the consolidation pressure, the fifth is the amount of sludge of a specimen, and the last is the initial water content.

Fig.5 through 10 show the results of the hydraulic

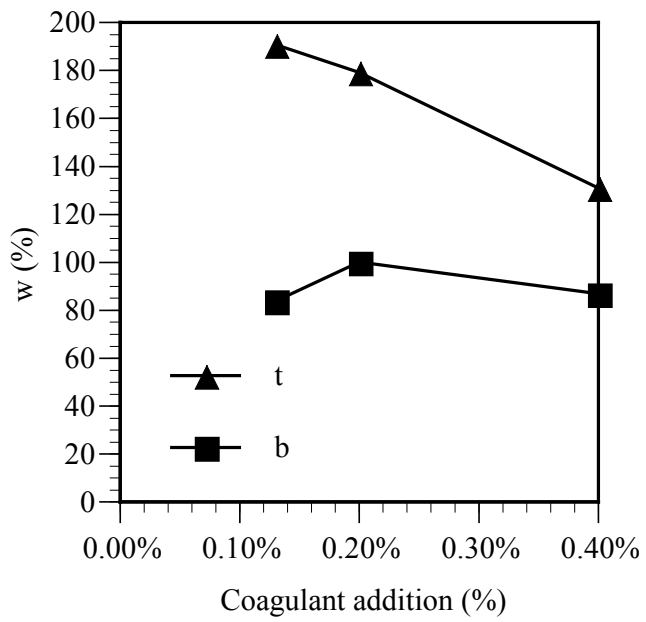

Fig.6 Relationship between the water content and the coagulant addition.

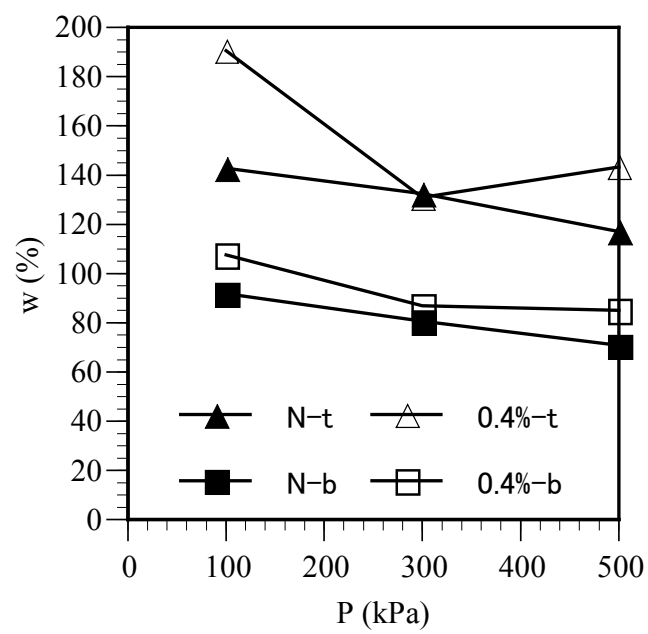

Fig.8 Relationship between the water content and the consolidation pressure.

consolidation tests. Water content at two points, namely, $1 \mathrm{~cm}$ below the surface and $1 \mathrm{~cm}$ over the bottom of a specimen is measured, and referred to ' $t$ ' and 'b', respectively, in these figures. Fig.5 gives the relationship between the water content and the air permeability of the four filter materials. The water content of the consolidated sludge is almost the same for all samples, because the permeability of sludge is smaller than the air permeability of filter materials. The final water content of sludge is affected by the permeability of sludge.

Fig.6 presents the relationship between the water content and the amount of the coagulant addition. The water content is decreased by adding coagulant, because of the resultant improvement of the permeability. Fig.7 depicts the relationship between the water content and the consolidation time. The consolidation time is seen to correlate with the final water content. The water content of the upper part of the consolidated sample decreases within one or two 


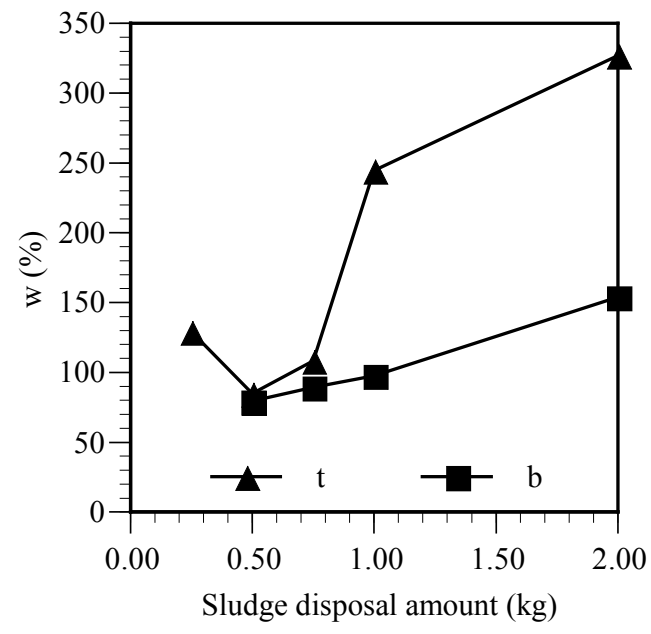

Fig. 9 Relationship between the water content and the amount of sludge disposal.

hours, while the clear water at the top of the specimen is wasted. Fig.8 provides the relationship between the water content and the consolidation pressure. " $0.4 \%$ - $\mathrm{t}$ " is dehydrated cake with a $0.4 \%$ stabilizer in the Figure. The water content of the sludge cakes decreases slightly under an increasing level of consolidation pressure. This fact might not be contradictory, because higher consolidation pressure makes the sludge faster to be dehydrated. The water content of the cakes dehydrated without a stabilizer is lower than that of the cakes dehydrated with a stabilizer.

Fig.9 describes the relationship between the water content and the amount of sludge disposal. The amount of sludge put into the machine has a more important role than the other factors, e.g., consolidation pressure and consolidation time in terms of the efficient dehydration with the filter press. The final water content in the case of $0.25 \mathrm{~kg}$ sludge becomes larger than that of $0.5 \mathrm{~kg}$ sludge since the $0.25 \mathrm{~kg}$ sludge is not enough to obtain the seepage force of water during the hydraulic consolidation. Fig.10 shows the relationship between the water content of the consolidated cakes and the initial water content. It can be seen from the figure that the water content of the consolidated specimen does not change with the initial water content under $500 \%$. When the initial water content is greater than $500 \%$, the consolidation time of 2 hours is not enough for supernatant solution to be expelled from the drain.

\section{CONCLUSIONS}

The concluding remarks from the test results are as follows:

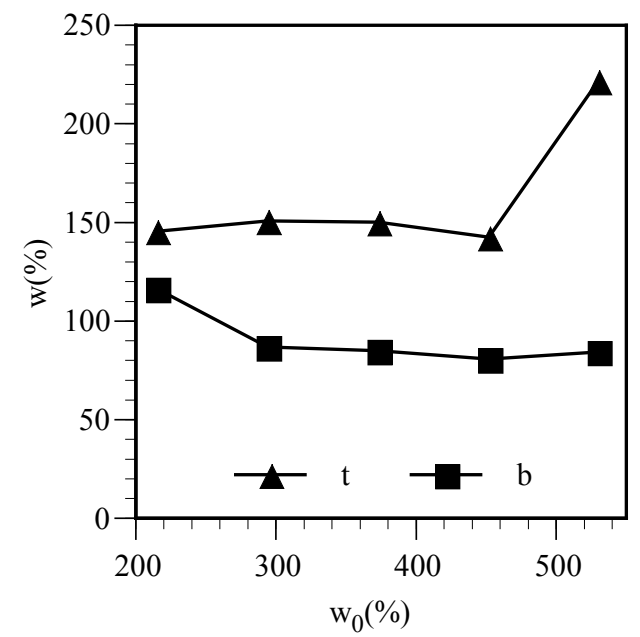

Fig.10 Relationships between the consolidated water content and the initial water content.

1. Different properties of in the four filter materials did not have much effect on the final water content of the sludge samples.

2. The water content of the cakes dehydrated without a stabilizer is lower than that of the cakes dehydrated with a stabilizer. However, it is confirmed that stabilizers can dehydrate sludge more quickly, because the coagulant improve permeability easily.

3. According to the laboratory test results, the efficiency of the dehydration can be increased if the amount of sludge put into the consolidation cell machine is decreased. These results suggest us that the dehydration chamber of an actual filter-press machine needs to be smaller in thickness in order to achieve effective in-situ dehydration.

\section{REFERENCES}

1) Fukushima, S., Kitajima, A., Ishiguro, K., Ikeda, Y., Sakamaki, K., and Tani, S. : Applicability of cement-stabilized pond-mud soil as embankment material for irrigation pond dam repairment, Journal of Structural Mechanics and Earthquake Engineering, No. 666, pp. 99-116, 2000 (in Japanese).

2) Hidaka, A., Kawanishi, A., Koyama, T., and Nagatsuka, N. : An examination about the effective use of the dredging soil by dewatering and solidification treatment, Proc. of the $41 \mathrm{st}$ Japan National Conference on Geotechnical Engineering, pp. 533-534, 2006 (in Japanese).

3) Nishimura, S., Takisawa, T., Murayama, Y., and Murakami, A. : Fundamental characteristics and improvement of dredged sludge cakes, Transactions of JSIDRE, No. 248, pp. 71-79, 2007 (in Japanese).

4) Imai, G. : Development of a new consolidation test procedure using seepage force, Soils of Foundations, vol. 19, No. 1, pp. 45-60, 1979.

(Received March 5, 2008) 